\title{
Raison D'etre Object: A Cyber-Hearth That Catalyzes Face-to-face Informal Communication
}

\author{
Takashi Matsubara $^{1}$, Kozo Sugiyama ${ }^{2}$ and Kazushi Nishimoto ${ }^{2}$ \\ ${ }^{1}$ Hitachi Ltd., Yoshida 292, Totsuka, Yokohama, 244-0817, Japan \\ T-matsuemsrd.hitachi.co.jp \\ 2 Japan Advanced Institute of Science and Technology, Asashidai 1-1, Tatsunokuchi, Nomi, \\ Ishikawa 923-1292, Japan \\ \{Sugi, Knishi\}@Jaist.ac.jp
}

\begin{abstract}
We propose a new concept, raison d'etre objects, and a new ware, cyber-hearth, that affords snugness in face-to-face communication in a shared informal place such as a refreshing room or lounge. We carried out observation experiments on the behavior of individuals in such a place and found interesting tendencies: most people behave unconsciously to pay attention to physical objects by watching or handling as excuses for entering or staying there. This might be because participants are unusually close each other in terms of proxemics. We developed a prototype cyber-hearth IRORI that incorporated raison d'etre objects with a facility for enhancing conversations, employing a metaphor 'hearth' ('irori' in Japanese) as a total design principle since 'irori' is well recognized as a snug, traditional informal place in Japan. We preliminarily evaluated IRORI by conducting a user experiment. The results of the experiment suggested that IRORI attained snugness and therefore were effective for catalyzing face-to-face informal communication.
\end{abstract}

\section{Introduction}

Nowadays the importance of face-to-face informal communication is well recognized [1]. Informal communication in an organization is indispensable elements for attaining targets of an organization harmonizing with formal activities. Most researches of informal communication support so far have inclined to researches of awareness support with video connections etc. in a distributed environment due to the fact that multi-site offices are expanding widely $[2,3,4]$. However, it is also important to study how to facilitate or catalyze communications in a shared informal place such as a refreshing room or lounge because we often get essential information and good ideas through informal communication in a relaxing and natural atmosphere. In other words, it is essential for participants to interact face-to-face in the same time and space for dealing with tacit knowledge that is difficult to be transmitted via electronic media [5].

In this research, we develop a prototype system called IRORI based upon the following hypothesis: "Snugness is the most important factor for facilitating or catalyzing communication in a shared informal place such as a refreshing room or lounge. An effective way for realizing snugness is that the system incorporates raison 
d'etre objects as system facilities and 'hearth' ('irori' in Japanese) metaphor as a total system design, where an 'irori' is a traditional fireplace in Japan."

Considerations to get the above hypothesis are as follows. The purpose of using a formal place such as a meeting room is usually limited and shared well among participants whereas in the case of a shared informal place it is usually not limited and not well shared. This means that time is needed for participants to adjust different intentions and interests. Therefore proxemics pressures [6] cause each participant an uncomfortable feeling in joining and staying still more if there is no active conversation in the space. To avoid proxemics pressures or attain snugness, each participant needs some reasons to justify still joining and staying there: usually appealing unconsciously to other participants that "I am paying attention to physical objects". Also often a conversation is started with talking about the object itself that some participant is touching or seeing. These mean that objects have effects of comfortableness or snugness to participants, which are called the effects of raison d'etre via objects and such objects are called raison d'etre objects. Thus, it is important for attaining snugness that the system incorporates such the effects.

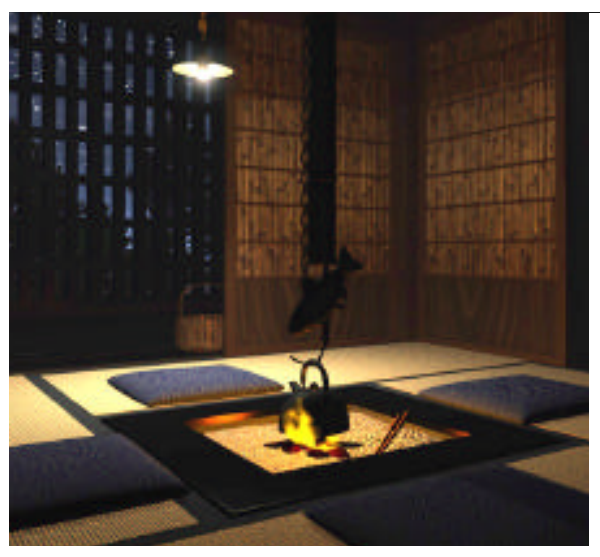

(a) a hearth

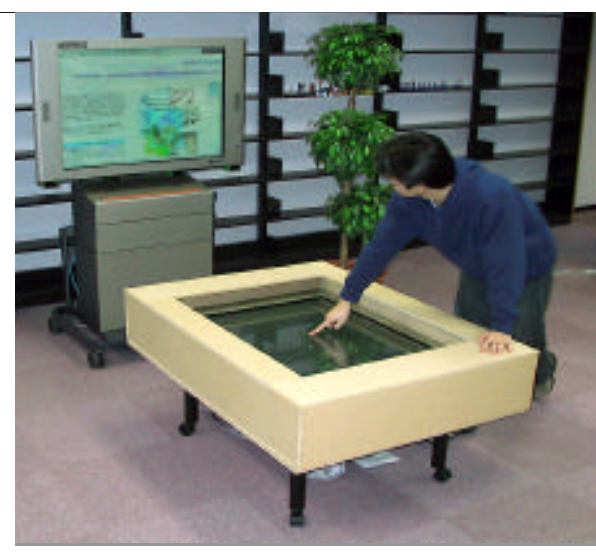

(b) a prototype cyber-hearth IRORI

Fig. 1. A real-hearth and a cyber-hearth. The left picture [7] shows a traditional hearth in Japan called 'irori' that is used for a snug living room. The right picture shows a prototype cyberhaerth IRORI we developed. We use 'hearth' metaphor for designing our system IRORI

It is convenient to have an adequate metaphor in designing a system. Fortunately we have a good instance for the metaphor called 'irori' that is a traditional hearth used for a snug living room with various objects (see Fig.1(a)). This informal place 'irori' is effective for facilitating informal communication in relaxing and natural atmosphere. Thus, we adopted this metaphor to develop our system.

In this paper we call a system that incorporates the effects of raison d'etre via objects and 'hearth' metaphor a cyber-hearth (see Fig.1(b)). It should be noted here that this metaphor is an extension of the concept, raison d'etre objects, into a wider, 
comprehensive concept emphasizing mental and social aspects as well as physical and informational aspects. Therefore, a cyber-hearth is relating to wares for supporting ' $\mathrm{Ba}$ ' [5] and cooperative buildings [8].

We took three steps approach: observation, implementation, and evaluation

\section{Observation Experiments in a Shared Informal Space}

We carried out observation experiments to investigate the behavior of individuals in a shared informal place: what are important factors and triggers for facilitating informal communication?

As the place for observation experiments we chose an open shared informal place (about $3.5 \mathrm{~m} \times 3.5 \mathrm{~m})$ situated in a center of a graduate student room $(16 \mathrm{~m} \mathrm{x} 16 \mathrm{~m} ; 16$ booths for students acquainted each other) in JAIST where there we re a round table (diameter $90 \mathrm{~cm}$ ), four chairs around it, and other things. The place was formed spontaneously in advance of the experiment just as a relaxing space with no special purpose and used frequently by several alternative participants to talk each other, read magazines and so on. Therefore it was the best place for our observation purpose. We arranged three video cameras and other things such as toys, boards, and magazines (see Fig. 2).

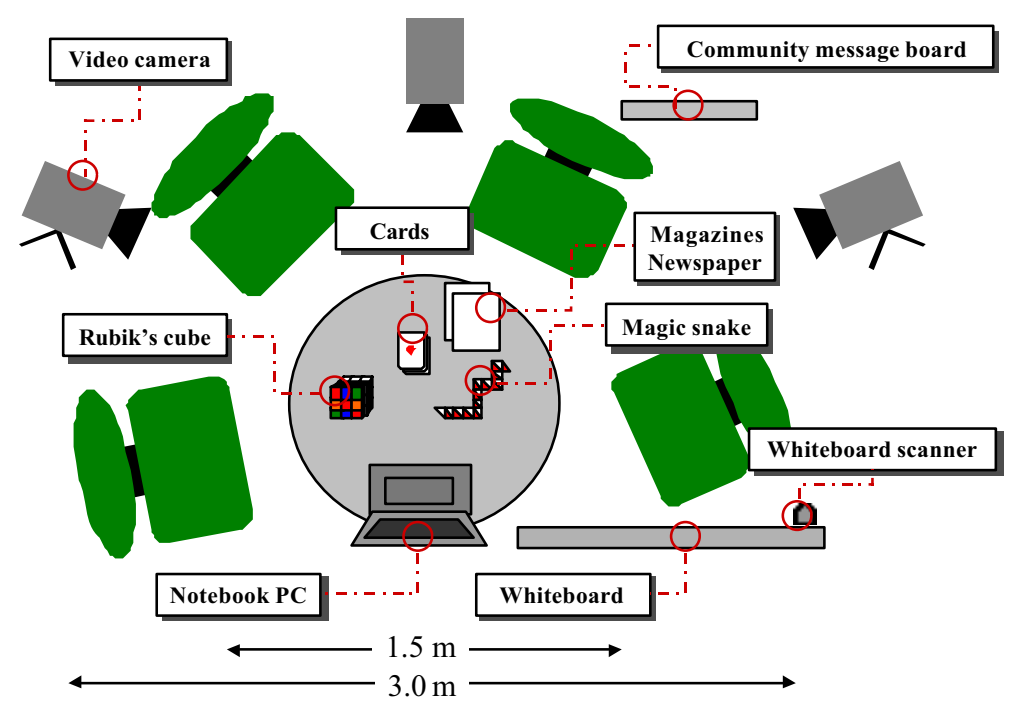

Fig. 2. The arrangement in an shared informal place used for our observation experiments.

We recorded the behavior of individuals by three video cameras for 7 days and analyzed the record. We first selected scene segments that include 5 or more minute talk by 3 or more participants but do not include taking foods or drinks. We got 16 scene segments. For each scene segment we carefully checked and described the movements of individuals (i.e., entering, staying, leaving, handling, seeing etc.), 
things participants saw or handled, triggers conversations were started or ended, and so on. An example for the description is as follows. "Participants A, B, and C. A is reading a magazine and $\mathrm{B}$ is handling cards. $\mathrm{C}$ enters and a conversation between $\mathrm{B}$ and $\mathrm{C}$ is started. $\mathrm{A}$ is sometimes joining the conversation while reading the magazine. In silence, each participant looks at different points. Participant A notices writings on the white board, both B and C look at it together, and a conversation is continued. B searches around him and holds a magazine, but $\mathrm{B}$ does not read it though turning over its pages. While conversations, B closes the magazine. A conversation is continued intermittently...." Fig. 3 shows scenes in the shared informal place.

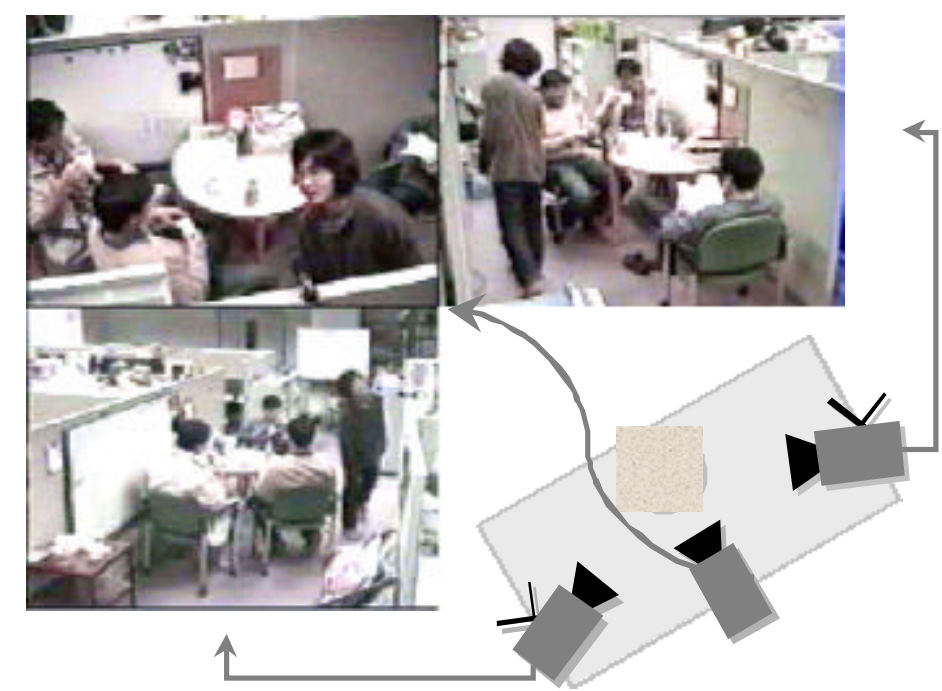

Fig. 3. Three pictures made from different directions at the same time in a shared informal place situated in the center of a graduate student room where the observation experiment was being conducted.

As the result of the observation experiments we found the following remarkable relationships between physical objects and participants behavior:

1. Behavior in entering: While approaching the table, most of individuals check who are around the table. However, after arriving there, usually a conversation is not started soon. They first begin to touch objects such as cards or magazines on the table or to see boards as if they came to the place for touching the objects or seeing boards.

2. Behavior in staying: Participants begin to talk about the object itself that someone is touching or seeing. Otherwise, a conversation is started gradually and intermittently without a clear direction. Sometime a conversation is active and sometime non-active. In both cases most of participants continue to handle or see the objects simultaneously. It seems that every participant is waiting a timing to join, begin, or re -begin a conversation rather than they are interested in just handling the objects. 
3. Time for which participants touch objects: It is remarkable that participants around the table are touching any object during $69.6 \%$ of the time in average.

The results of the experiment well support our hypothesis described above. From the above relationships, it is suggested that the existence of physical objects gives participants chances for starting a conversation and reasons for justifying "enter there" and "stay there".

The necessity of raison detre objects can be supported from a viewpoint of proxemics. People possess unspoken proxemics rules for appropriate distances in daily relationships [6]. It is proposed that the distances are categorized into the five zones according to the possibilities for starting a conversation [9]. Among them the following zones are interesting for us:

1. Zone of conversation $(50 \mathrm{~cm} \sim 1.5 \mathrm{~m})$ : When this zone is entered, a conversation is mandatory.

2. Zone of proximity $(1.5 m \sim 3 m)$ : It is possible to enter this zone without starting a conversation for the time being.

Our shared informal place used for the observation experiment has the critical size where it is mandatory to start a conversation or not (see Fig.2). This might be a reason why the raison d'etre effects of objects were observed in the place. Fig. 4 illustrates possible models of mutual awareness among participants in the shared informal place.

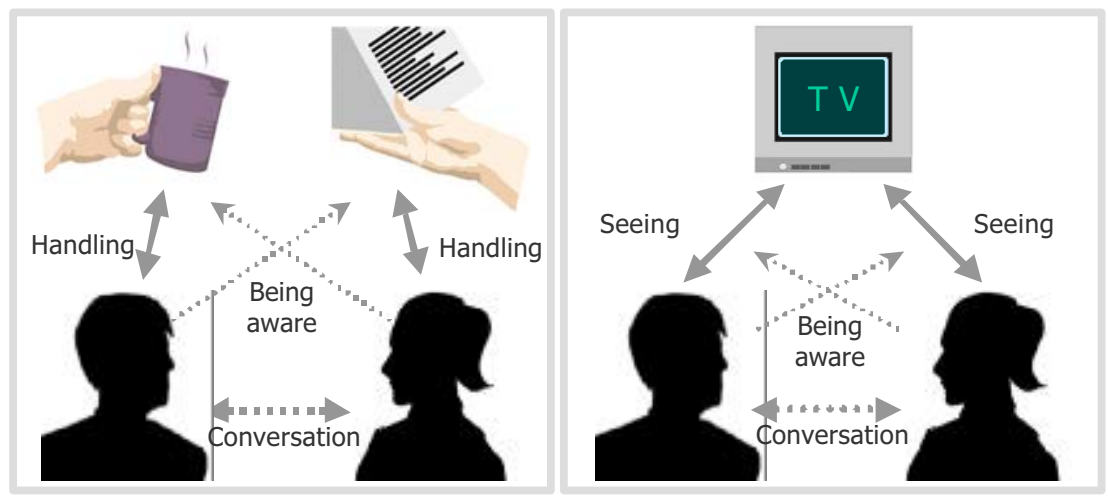

Fig. 4. Possible models for the effects of justifying via objects. Both participants are aware of behavior of handling (left) or seeing (right) each other. This situation becomes excuses (or raison d'etre) to each other for entering or staying there

\section{A Prototype Cyber-Hearth IRORI}

In order to develop a prototype system to facilitate communication in a shared informal place, we adopted two design principles. One of them is a general principle: our system should be like "irori" both physically and mentally because "irori" was a comfortable, traditional shared informal place with a long history. It has been used for multiple informal purposes such as cooking, eating, lighting, warming, and talking. 
We wish that our system will become a digital "irori" in offices and schools in the near future. The other one is that our system should incorporate the raison d'etre effects of objects. There also exist various objects including fire, charcoals and a kettle around a traditional "irori" used for the above purposes. In our view, these objects play the role of easing "enter there" and "stay there" like a catalyst.

The first principle can be broken down into the following requirements: (I1) the physical design of our system should be a "irori" style, and (I2) our system should afford comfortableness or relaxation but avoid tiredness. For the second principle we can break down "stay there" effect into three requirements: (S1) the system should have elements (i.e., objects) that the user can touch, control, and/or see, (S2) the user can readily touch or stop to touch the elements at will, and (S3) user's behavior to touch them should not look like unnatural. We can beak down the "enter there" effect into three requirements: (E1) the system should provide such information as the user can not see it in any other place in surroundings, (E2) objects and their contents should change frequently so that it is useful for the user to see them, and (E3) the user's behavior to see them should not look like unnatural.

We implemented a prototype system called IRORI according to the above requirements. The system offers the following facilities:

1. Physical arrangement for a shared informal place in "irori" style: A traditional "irori" has been continuously sophisticated in terms of snugness (i.e., communicability, familiarity, and comfortableness) for a long time. Therefore, seeking similarity to an "irori" style in designing our system must be meaningful. Fig.5 shows IRORI system that has the appearance similar to "irori". This facility satisfies requirement I1.

2. Direct manipulation of water and vapors in $3 D$ space by fingers: This facility is intended to satisfy requirements $\mathrm{I} 2, \mathrm{~S} 1$, and $\mathrm{S} 2$. We realize water and vapors in 3D space instead of fire and charcoals of 'irori'. Water and vapors are shown on a big plasma display (PDP) covered by a touch panel. We can control the movement of vapors by fingers. We might have a tendency to be fond of touching water and vapors that give us relaxation effects. Moreover, water and vapors dynamically and complicatedly changes and therefore this never make us feel tiredness.

3. Dynamic presentation of Web contents hidden in vapors for enhancing conversations: This facility is intended to afford topics for enhancing conversations while a reathearth cannot provide such the facility via fire and firewood (or charcoals). Each vapor has a connection to a Web page. The rule for the connection can be defined according to the user's convenience. Currently it is linked to a page that some members in an organization had accessed previously. Each member is identified by color. When the user touches a vapor and attains specific conditions, the page is displayed on another horizontal PDP settled near. This facilities satisfies requirements E1, E2, and E3.

4. Non-simple operation for searching and controlling vapors: The specific conditions to display Web pages are not known by the user. The user has to search and find them. Therefore, this facility satisfies requirement S1.

IRORI consists of three parts: a main part for displaying water and vapors on a PDP, a part for displaying Web pages on another PDP, and a proxy server. These parts are connected via network (see Figs. 1(b), 5 and 6). 


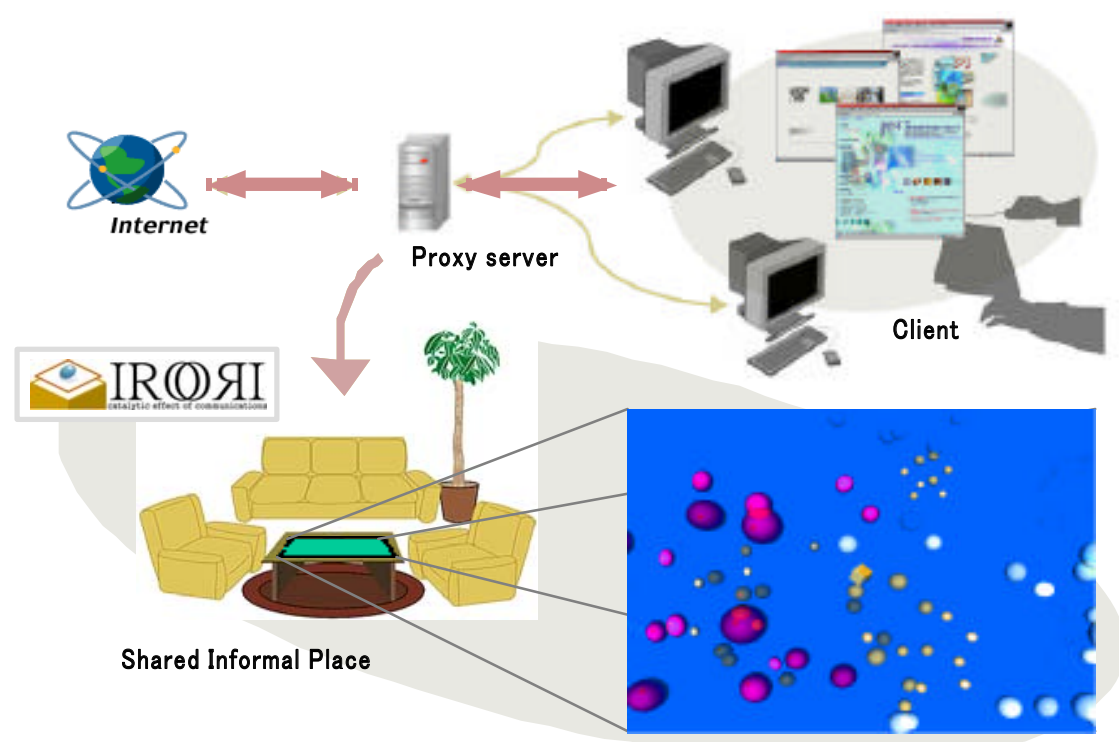

Fig. 5 . Structure of IRORI system. Each vapor on the screen of horizontal PDP is linked to an URL that a client had accessed previously
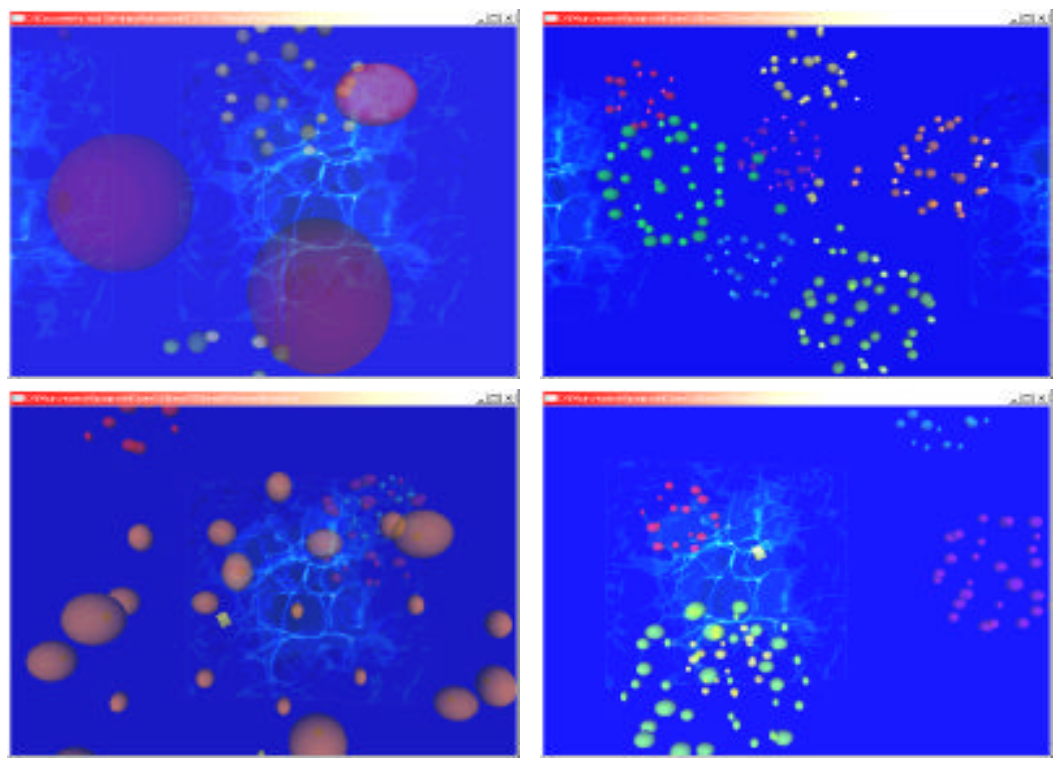

Fig. 6. Snapshots of the screen of the horizontal PDP 


\section{Preliminary User experiment for Evaluating IRORI}

Evaluation Experiments are preliminarily carried out in terms of "stay there" (see Fig.7). Our concern exists mainly in evaluating how intensely the user of IRORI feels snugness comparing with the cases without using IRORI. Moreover, we are interested in relationships among objects, conversation, and snugness.

We prepared three different experimental environments: (a) BASE: an environment where there is only a table and nothing on it, (b) LEAFLET: an environment where there are a table and leaflets on it, and (c) IRORI environment. Five groups of subjects were formed and each group consisted of three subjects. A session for each group was planed as the following schedule (126 minutes):

1. Explanation on experiments to the subjects

2. Communication in environment BASE $15 \mathrm{~min}$

3. Rest $3 \mathrm{~min}$

4. Communication in environment LEAFLET $15 \mathrm{~min}$

5. Rest $3 \mathrm{~min}$

6. Explanation on IRORI system $5 \mathrm{~min}$

7. Use of IRORI (not recorded) $5 \mathrm{~min}$

8. Communication in environment IRORI $15 \mathrm{~min}$

9. Rest $5 \mathrm{~min}$

10. Questionnaire (replayed) $60 \mathrm{~min}$.

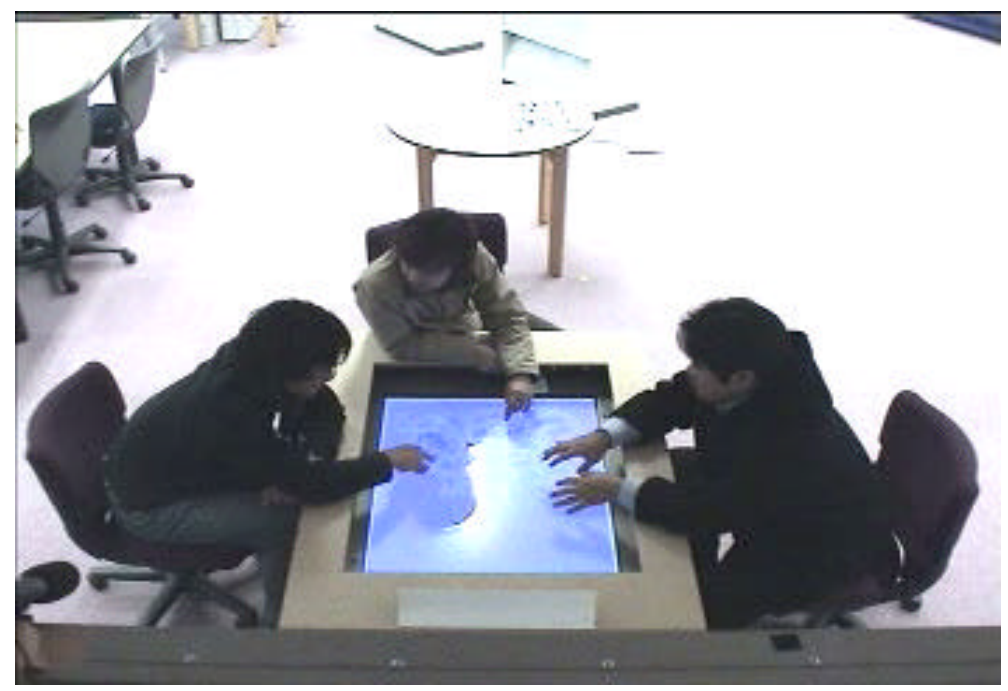

Fig. 7. Three subjects are using IRORI in the evaluation experiment

Scenes of all the sessions were recorded by a video camera. For each session three subjects who were acquainted each other were asked to make communication in an own way, i.e., having a conversation were not requested. After the sessions, all 
subjects were requested to reply to a questionnaire through looking at the replay of video records. In the questionnaire each subject were asked to give evaluation values ( 0 : none, 1 : lowest,..., 5: highest) for the following four evaluation items at every 30 seconds: (a) CONVERSATION: Intensity of interest in the conversation, (b) LOOK: Intensity of interest in the looking object, (c) TOUCH: Intensity of interest in the touching object, and (d) SNUGNESS: Intensity of snugness.

The following suggestions were obtained from statistic analyses of these values.

1. In BASE environment, a high correlation between CONVERSATION and SNUGNESS appears in most case. This means that in BASE environment a conversation is important for making snugness better. This is naturally accepted in our experience.

2. In IRORI environment a correlation between CONVERSATION and SNUGNESS becomes lower than BASE case but SNUGNESS is higher than the other two environments. This means that the behavior of touching objects (i.e., water and vapors of IRORI) compensates the lack of a conversation and makes snugness higher than the other two. This result is very important because it suggests that the raison d'etre effect of objects is effective in IRORI environment.

3. A correlation between TOUCH and SNUGNESS in IRORI environment is higher than the same correlation in LEAFLET environment. TOUCH and LOOK in IRORI environment are relatively higher than the other cases. These results also suggest the raison d'etre effect of objects in IRORI system.

\section{Concluding Remarks}

We have investigated a system to facilitate face-to-face informal communication among people of an organization that occurs spontaneously in a shared informal place such as a refreshing room or lounge. Our research based on the hypothesis that snugness is the most important factor for the informal communication support and it is effective for developing the system to incorporate a newly proposed concept 'raison d'etre object' and "irori" metaphor. We made observation experiment to analyze behavior of participants in a shared informal place and found two kinds of effects of justifying via objects: "enter there" and "stay there". Then we developed a prototype system called IRORI that incorporated both the raison detre object and "irori" metaphor. We carried out preliminary a user experiment to evaluating IRORI system based on questionnaire methods. The results of the experiments have suggested that the user of IRORI system feels snugness more than other environments.

\section{References}

1. Matsushita, Y., Okada, K.: Collaboration and Communication. Kyoritsu-shuppan. (1995)

2. Tang, J., Ruaa, M.: Montage: Providing Teleproximity for Distributed Groups. Proc. CHI'94, ACM, Boston. (1994) 37-34 
3. Obata, A., Sasaki, K.: OfficeWalker: A Virtual Visiting System Based on Proxemics. Proc. ACM 1998 Conference on Computer Supported Cooperative Work, Seattle. (1998) $1-10$

4. Dourish, P., Bly, S.: Portholes: Supporting Awareness in Distributed Work Group. Proc. CHI'92, ACM. (1992) 541-547

5. Nonaka, I., Konno, N.: The Concept of 'Ba': Building a Foundation for Knowledge Creation. California Management Review. 40-3 (1998) 40-54

6. Hall, E. T.: The Hidden Dimension. Doubleday. New York. (1966)

7. http://www.kt.rim.or.jp/ noir_/irori.html

8. Streitz, N. A., Geithler, J., Holmer, T.: Roomware for Cooperative Buildings. Proc. CoBuild'98, Darmstadt. (1998) 4-21 (Springer LNCS 1370)

9. Nishide, K.: Distance Between a Hu man and a Human. Architect and Business. 5 (1985) 95-99 (in Japanese) 